\author{
Miguel Angel Tola \\ María Isabel Yugueros \\ Nieves Fernández-Buey \\ Rosario Fernández-Herranz
}

\section{Prevalence of multiple sclerosis in Valladolid, northern Spain}

Received: 4 March 1998

Received in revised form: 13 May 1998 Accepted: 10 June 1998

M. A. Tola Arribas (区) - M. I. Yugueros N. Fernández-Buey · R. Fernández-Herranz Department of Neurology, Hospital Universitario de Valladolid, Mailing address: C/ Embajadores 20 6B, S-47013 Valladolid, Spain Fax: +34-83-39-0357

\begin{abstract}
The aim of this study was to ascertain the prevalence of multiple sclerosis (MS) in a northern Spanish region and to compare it with that from the most recent epidemiological studies in the country. MS prevalence was studied for a period of 2 years using multiple sources of information in the province of Valladolid, with a sample comprising a total population of 92,632. Patients were classified according to the Poser criteria. The
\end{abstract}

crude prevalence of definite and probable MS was 58.3 per 100,000 (95\% confidence interval: 43.7-75.7). The same methods have been used in ascertaining similar prevalence rates in Vélez-Málaga, Osona, and Gijón and a slightly lower rate in Teruel. Our survey confirms Spain as a highrisk area for MS, with prevalence rates over 50 per 100,000.

Key words Multiple sclerosis . Prevalence $\cdot$ Spain

\section{Introduction}

Surveys on the prevalence of multiple sclerosis (MS) carried out in large populations in Spain before 1992 used various diagnostic criteria and were based almost exclusively on hospital records $[1,2,6,8,14,16,18,25$, $28,29]$. These studies defined Spain as an area of low to medium risk for MS, according to Kurtzke [12]. Using every reasonable information source available for populations under 100,000, prevalence rates between 32 and 65 per 100,000 in northern and southern Spain have been obtained [3, 7, 17, 30]. Dean and Middleton used the same methods and reported similar figures for Sicily and Cyprus, at a latitude similar to that of Spain, $[4,15$, 26].

Except for a previous survey in Salamanca and Zamora [25], there are no recent data on the frequency of MS in our region, located $200 \mathrm{~km}$ north of Madrid. Nevertheless, the number of followed-up patients in our health area suggested the prevalence of MS here to be similar to that recently reported for the north and south of our country.

\section{Study population and methods}

The area investigated includes six health zones, each of with its own health center and with a single outpatient clinic of specialties run by the Neurology Department of the Hospital Universitario of Valladolid. These six areas are within the city of Valladolid and comprise a total area of $197 \mathrm{~km}^{2}\left(41^{\circ} 39^{\prime} \mathrm{N}-4^{\circ} 44^{\prime} \mathrm{W}\right)$ and a population of 92,632 (November 1996). The region has a continental climate with a mean temperature of $12.4^{\circ} \mathrm{C}$. Its average altitude is $698 \mathrm{~m}$ above sea level (Fig. 1). Economic activity is fundamentally industrial, largely car and machinery manufacturing, and services. The population level in Valladolid is stable, having increased only slightly over the past 15 years. There is a high racial uniformity and migratory movements are rare.

The survey was carried out over a 2-year period from September 1995 to August 1997. The day of 1 March 1997 was chosen as the prevalence day since this was the date when all the patients began to be checked for the second time to confirm they were still alive and living in the area. Poser's classification of MS was used, and only those persons with probable or definite MS were included 
[22]. Disability was assessed using the Expanded Disability Status Scale (EDSS) of Kurtzke [10]. A disability of 0-3 was considered mild disability, 4-6 moderate disability, and 7-9.5 severe disability. A progression index was defined as the ratio of the disability status (EDSS) to the duration of the disease in years [21]. The type of progression was defined according to the consensus criteria established by Lublin et al. [13]. The onset of MS was determined by interviewing patients and reviewing their medical records, and the classification of definite and probable signs and symptoms of MS proposed by Poser was used [19].

Multiple methods for case ascertainment were used. Records of both Valladolid hospitals (Hospital Universitario and Hospital Universitario del Río-Hortega), data from the Neurology Service of the Hospital Universitario and the records from outpatient clinics of specialties were reviewed, searching for the code number 340 (MS). Further information was obtained from 41 general practitioners in the area by periodically interviewing medical coordinators from each one of the six health zones. Other sources of information included private neurologists (4), internists (14), records of evoked potential studies in Hospital Universitario, a home hospitalization unit, welfare workers, and the local MS patient association. Information from the city's two units of magnetic resonance imaging (MRI) could not be obtained as their files were not on a data base. Searching for nonidentified patients, two symposia for relatives and patients were held and reported by the public media.

All possible MS patients were examined by two neurologists. A second examination was carried out by the same physician in all cases. MS had to be confirmed by both physicians for the diagnosis to be accepted.
Adjusted prevalence rates were calculated by the direct method [11] using 5-year groupings, with the total Spanish population (1991 census) as a standard. Confidence intervals $(95 \%)$ were computed assuming the Poisson distribution [27]. The chi-square test was used to analyze the homogeneity in the distribution of patients over the six health zones [9]. The survey was reviewed by the Hospital Universitario of Valladolid Research Committee and by the Board of the ONCE Foundation for the cooperation and social integration of the disabled.

\section{Results}

After an intensive search, 54 definite or probable MS patients were ascertained, all alive and living in the area on 1 March 1997 (18 men and 36 women). Fifty-one patients had definite MS (18 men and 33 women), including 4 with laboratory-confirmed MS. Three women had clinically probable MS. The crude prevalence rate found in the area was 58.3 per 100,000 (95\% CI: 43.7-75.7). The prevalence for clinically definite MS alone was 55.1 per 100,000. Age- and sex-specific prevalence rates are shown in Table 1 . The distribution of cases within the study area, analyzed according to the six health zones, was uniform (chi-square $=7.2$; d.f. $=5 ; P=0.2$ ). Crude prevalences and age- and sex-adjusted prevalence rates of the 1991 Spanish population in the most recent epidemiological studies carried out in Spain are shown in Table2.

Forty-five patients were visited or admitted to hospital during the study. Five patients were identified by hospital records. One patient was being visited by a private neurologist and another patient by an internist. The collabora-
Fig. 1 Map of Spain, with the province of Valladolid (left) and the study area (right). The areas of Gijón, Osona, Teruel, and Vélez-Málaga are also shown

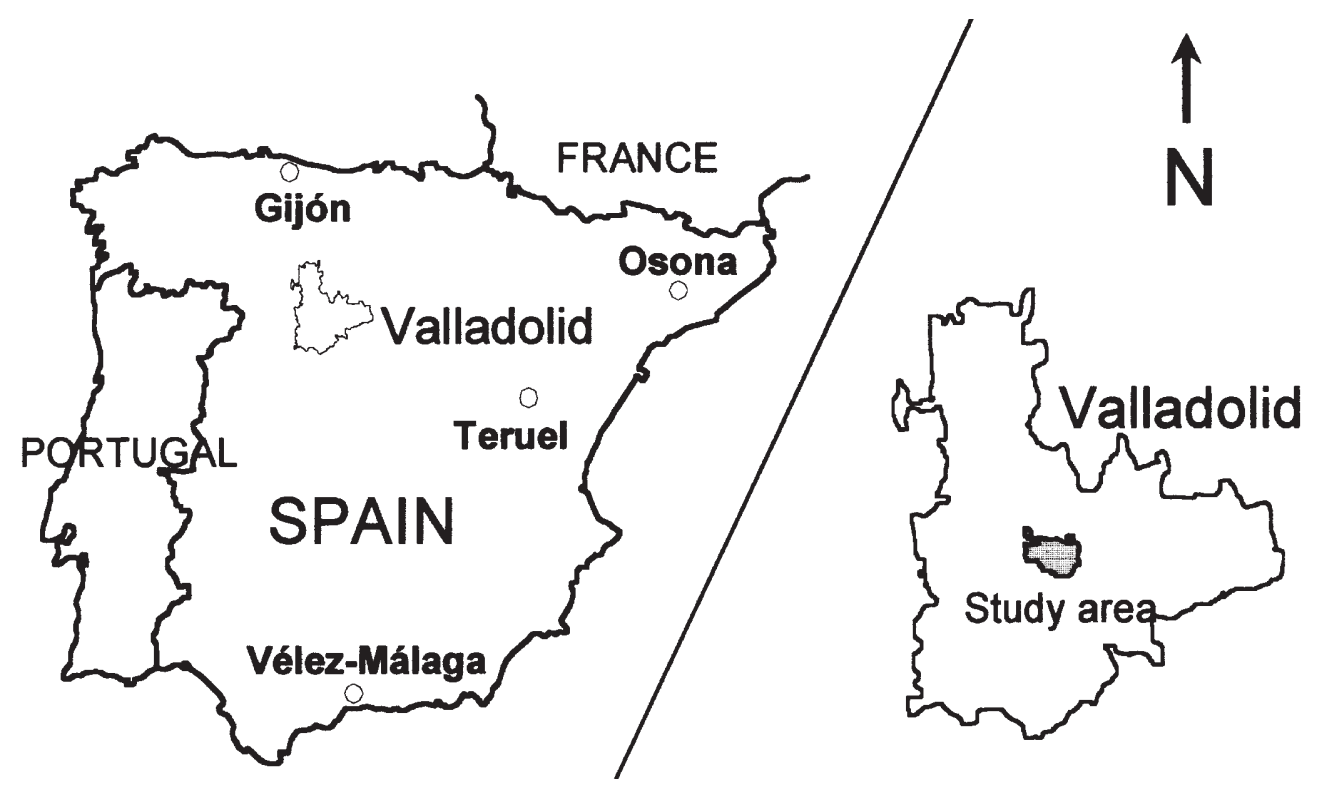


Table 1 Age- and sex-specific prevalence rates ( $M S$ multiple sclerosis, $M$ men, $W$ women)

\begin{tabular}{|c|c|c|c|c|c|c|c|c|c|}
\hline \multirow{2}{*}{$\begin{array}{l}\text { Age } \\
\text { (years) }\end{array}$} & \multicolumn{3}{|c|}{ Population } & \multicolumn{3}{|c|}{ MS patients } & \multicolumn{3}{|c|}{ Prevalence/100,000 } \\
\hline & M & W & Total & M & W & Total & M & W & Total \\
\hline$\leq 19$ & 9,044 & 8,822 & 17,866 & 2 & 2 & 4 & 22.1 & 22.7 & 22.4 \\
\hline $20-29$ & 9,412 & 9,579 & 18,991 & 6 & 12 & 18 & 63.7 & 125.3 & 94.8 \\
\hline $30-39$ & 6,067 & 6,580 & 12,647 & 2 & 12 & 14 & 33 & 182.4 & 110.7 \\
\hline $40-49$ & 6,014 & 6,844 & 12,858 & 3 & 5 & 8 & 49.9 & 73.1 & 62.2 \\
\hline $50-59$ & 5,794 & 5,899 & 11,693 & 5 & 4 & 9 & 86.3 & 67.8 & 77 \\
\hline$\geq 60$ & 7,921 & 10,656 & 18,577 & - & 1 & 1 & - & 9.4 & 5.4 \\
\hline All & 44,252 & 48,380 & 92,632 & 18 & 36 & 54 & 40.7 & 74.4 & 58.3 \\
\hline
\end{tabular}

Table 2 Comparison of the most recent prevalence studies in Spain ( $M S$ multiple sclerosis, $C I$ confidence interval)

\begin{tabular}{lrlll}
\hline & $\begin{array}{l}\text { Popu- } \\
\text { lation }\end{array}$ & $\begin{array}{l}\text { MS pa- } \\
\text { tients }\end{array}$ & $\begin{array}{l}\text { Crude } \\
\text { prevalence } \\
{[\text { [CI 95\%] }}\end{array}$ & $\begin{array}{l}\text { Age- and } \\
\text { sex-adjusted } \\
\text { prevalence }^{\mathrm{b}}\end{array}$ \\
\hline Vélez-Málaga [7] & 36,014 & 19 & $52[31.7-82.2]$ & 61 \\
Osona [3] & 71,985 & 42 & $58[42.0-78.7]$ & 60 \\
Gijón [30] & 33,775 & 22 & $65[40.8-98.3]$ & 59 \\
Teruel [17] & 143,680 & 46 & $32[22.8-41.3]$ & 35 \\
Valladolid & 92,632 & 54 & $58[43.7-75.7]$ & 53 \\
\hline
\end{tabular}

${ }^{\text {a }}$ Crude prevalence per 100,000 population

${ }^{\mathrm{b}}$ Age- and sex-adjusted prevalence per 100,000 in the 1991 Spanish population

tion of the local MS patient association allowed us to find one patient not identified by other methods. A general practitioner reported the case of a woman suffering from MS for 24 years who had not been visited by a neurologist for the past 10 years. The remaining methods for case ascertainment detected no patient not already known by the local neurologists.

Mean age at onset was 27.3 years (men 28.7, women 26.6) and mean age on the prevalence day was 36.1 years (men 37.6, women 35.3). The mean period between the first symptom and the prevalence day was 8.7 years (men 8.8; women 8.6). The mean diagnostic delay was 3 years (range 0-23). Sensory symptoms were the most common at onset $(55 \%)$, followed by pyramidal tract symptoms (49\%), brainstem symptoms (31\%), cerebellar symptoms (24\%), and optic neuritis (14\%).

Cranial MRI was performed in all patients except three, with abnormal results in $98 \%$. In addition, the results of $32 \%$ of spinal MRI studies were also abnormal.

The median and interquartile EDSS range in clinically definite patients was 3.0 [1.5-5.0; men 3.5 (1.5-5.6), women 2.5 (1.0-4.3)]. The mean EDSS score was 3.4. The mean progression index was 0.4. Among these patients $58 \%$ were only slightly or not disabled (EDSS $\leq$ 3.0 ), and $13 \%$ were severely disabled (EDSS $\geq 7.0$ ). Nine patients were alive after 15 years of the disease; one had low disability, four moderate, and four severe.
The clinical course was relapsing-remitting in $37 \mathrm{pa}-$ tients $(68 \% ; 11$ men, 26 women), primary-progressive in 11 (20\%; 4 men, 7 women), and 6 patients with an initial relapsing-remitting evolution had developed a secondary progressive clinical course ( 3 men, 3 women).

Thirty-four patients were born in Valladolid (63\%), ten in adjacent provinces (18\%), and the rest in other places in Spain, except two patients born in France and Switzerland, respectively. A family history of MS were found in two women.

Nine patients were excluded from the survey because they had been misdiagnosed. Two of these had a cervical spondylotic myelopathy; one had an Arnold-Chiari malformation; three had hyperintense lesions on cranial MRI that according to their vascular risk factors, clinical course, and age was of ischemic origin; one was diagnosed as having Childer disease, though not confirmed by necropsy; one showed typical hyperintense lesions on cranial MRI although his symptoms were considered secondary to a large cervical disk herniation; and one suffered from hysteria.

\section{Discussion}

The results of our study, together with those obtained in other Spanish regions using a similar methodology [3, 7, $17,30]$, confirm our country as a high risk area for MS, with prevalence rates between 50 and 60 per 100,000 . We believe that only a single further study in southern Spain is needed to confirm the survey findings of Fernández et al. $[6,7]$ in Málaga.

Comparison of adjusted prevalence rates to Spanish populations, except for the results of Modrego-Pardo et al. in Teruel [17], show few differences among the recent surveys carried out in Spain. The size of the study area, with a total population of 143,000 inhabitants, health-care dispersion, duration of the survey, and a high emigration rate can explain the prevalence rate in Teruel.

A number of features lend additional credence to the figures from our study. The study population has a high demographic stability and racial uniformity. The area has a good sanitary infrastructure, with well-developed health 
services, and neurological care is focused in a single neurology department. Computerization of both hospital records and neurology service data made case ascertainment easier. Multiple sources of information as by Fernández et al. were used [5], allowing us to identify nine patients $(16 \%)$ who were not being visited by local neurologists. If we had not used all these information sources, the prevalence figures would have been 48.6 instead of 58.3 per 100,000 . Finally, the patient distribution in the studied area was homogeneous, showing easy and uniform access to neurological services.

It has been proposed as a measurement of the reliability of MS prevalence studies that the ratio of patients having a low degree of disability (EDSS $\leq 3.0$ ) must be close to $70 \%$ [24]. This estimation has been carried out according to the concept of onset-adjusted prevalence rate proposed by Poser, after his experience on a survey in Iceland [23]. This measures the number of symptomatic MS patients (diagnosed or not) in an ethnically homogeneous population who live to the age of puberty in the same naturally defined geographical area [20]. This measurement requires case ascertainment to be extended at least 2 years after the prevalence date to increase the probability of diagnosing all the patients in the area. In our study, using the traditional concept of prevalence, the ratio of patients with low disability was $58 \%$. This lower percentage suggests that there may be patients who have not consulted health services for their symptoms yet.

The mean age on the prevalence day (36.1 years), the mean duration of the disease ( 8.7 years), the reduced percentage of patients with a secondary progressive course, and the low number of patients older than 60 years suggest that there are some patients in the area who were not identified in this study. Our accumulated experience could clarify this point in a future survey.

Acknowledgements We thank Drs. J. Marco, J. M. Gutiérrez-García, J. Gómez-Nieto, A. Romeralo, M. Aparicio, P. Espino, and M. Toledano for their help in case ascertainment. We also thank the Asociación Vallisoletana de Esclerosis Múltiple and the patients for their collaboration in the study. This study was financed by the ONCE Foundation for the cooperation and social integration of the disabled.

\section{References}

1. Antón-Aranda E, Martínez-Lage JM, Maraví E, Gállego J, de Castro P, Villanueva JA (1991) Epidemiología y aspectos clínico-evolutivos de la esclerosis múltiple en Navarra. Neurología 6 : 160-169

2. Barduzal-Anglés S, Oliveros A, Manubens JM, Morales F (1987) Esclerosis múltiple: estudio epidemiológico retrospectivo en Aragón (1975-1985). Neurología 2:97-100

3. Bufill E, Blesa I, Galán I, Dean G (1995) Prevalence of multiple sclerosis in the region of Osona, Catalonia, northern Spain. J Neurol Neurosurg Psychiatry 58:577-581

4. Dean G, Savettieri G, Giordano D (1981) The prevalence of multiple sclerosis in Sicily. II. Agrigento city. J Epidemiol Community Health 35 : $118-122$

5. Fernández O, Bufill E (1994) Prevalencia de la esclerosis múltiple en España: validación de un protocolo epidemiológico de dos áreas geográficas separadas. In: Hernández MA, Fernández O (eds) Nuevas perspectivas en el diagnóstico de la esclerosis múltiple. Prous, Barcelona, pp 5-10

6. Fernández O, Izquierdo G, Campos VM, Pastor M (1986) Epidemiología de la esclerosis múltiple en la provincia de Málaga (España) Un estudio de prevalencia. Neurología 1:3-5
7. Fernández O, Luque G, San Román C, Bravo M, Dean G (1994) The prevalence of multiple sclerosis in the sanitary district of Vélez-Málaga, southern Spain. Neurology 44:425-429

8. García JR, Rodríguez S, Sosa Enríquez M, Batista E, Corujo E, Font de Mora Turón A, Hernandez Hernandez E, Betancor León P (1989) Prevalence of multiple sclerosis in Lanzarote (Canary Islands). Neurology 39:265-267

9. Kurtzke JF (1966) On statistical testing of prevalence studies. J Chronic Dis 19 :909-922

10. Kurtzke JF (1983) Rating neurologic impairment in multiple sclerosis: an expanded disability status scale (EDSS). Neurology 33 : 1444-1452

11. Kurtzke JF (1984) Neuroepidemiology. Ann Neurol 16:265-277

12. Kurtzke JF (1995) MS epidemiology world wide. One view of current status. Acta Neurol Scand [Suppl 161]:23-33

13. Lublin FD, Reingold SC (1996) Defining the clinical course of multiple sclerosis: results of an international survey. Neurology 46:907-911

14. Matías-Guiu J, Bolumar F, Martín R, Insa R, Casquero P, Moltó JM, Calatayud E, Aranaz J (1990) Multiple sclerosis in Spain: an epidemiological study of the Alcoy health region, Valencia. Acta Neurol Scand 8:479-483

15. Middleton LT, Dean G (1991) Multiple sclerosis in Cyprus. J Neurol Sci 103: 29-36
16. Miró J, Rebollo M, Combarros O, Polo JM, Leno C, Berciano J (1984) Esclerosis múltiple en Cantabria. Estudio retrospectivo de 30 casos. Rev Clin Esp $175: 153-156$

17. Modrego-Pardo PJ, Pina-Latorre MA, López A, Errea JM (1997) Prevalence of multiple sclerosis in the province of Teruel, Spain. J Neurol 244: 182-185

18. Oliveras de la Riva C, Aragonés Olle JM, Mercadé Sobreques J (1968) Estudio de la incidencia relativa y absoluta de la esclerosis múltiple en nuestra región. Anales de Medicina y Cirugía (Barcelona) 54:13-15

19. Poser CM (1994) The epidemiology of multiple sclerosis: a general overview. Ann Neurol 36 [Suppl 2] : 180-193

20. Poser CM (1995) Notes on the epidemiology of multiple sclerosis. J Formos Med Assoc 94:300-308

21. Poser S, Raun NE, Poser W (1982) Age at onset, initial symptomatology and the course of multiple sclerosis. Acta Neurol Scand 66:355-362

22. Poser CM, Paty DW, Scheinberg L, McDonald WI, Davis FA, Ebers GC, Johnson KP, Sibley WA, Silberberg DH, Tourtellotte WW (1983) New diagnostic criteria for multiple sclerosis: guidelines for research protocols. Ann Neurol 13:227-231

23. Poser CM, Benedickz J, Hibberd P (1992) The epidemiology of multiple sclerosis. The Iceland model. J Neurol Sci $111: 143-152$ 
24. Rosati G (1994) Descriptive epidemiology of multiple sclerosis in Europe in the 1980s: a critical overview. Ann Neurol 36 [Suppl 2] : 164-174

25. Ruiz-Esquerro JJ, Ortín A, López-Alburquerque JT, López-García M, Cacho J (1988) Epidemiología de la esclerosis múltiple en Salamanca y Zamora. Neurología 3 [Suppl 1]:57
26. Savettieri G, Daricello B, Giordano B, Karhausen L, Dean G (1981) The prevalence of multiple sclerosis in Sicily. I. Monreale city. J Epidemiol Community Health 35:114-117

27. Schoenberg BS (1983) Calculating confidence intervals for rates and ratios. Simplified method utilizing tabular values based on the Poisson distribution. Neuroepidemiology 2:257-265

28. Sosa M, Betancor P, Rosas C, Navarro MC (1983) La esclerosis múltiple en la provincia de las Palmas. Archivos de Neurobiología (Madrid) 46:161-166
29. Uría DF, Virgala P, Alonso P, Crespo JR, Calatayud P, Arribas JM (1991) Epidemiología de la esclerosis múltiple en Asturias. Neurología 6:41-45

30. Uría DF, Abad P, Virgala P, Díaz A, Chamizo C, Calatayud MT, Dean G (1996) Epidemiología de la esclerosis múltiple en Gijón. Un estudio de base poblacional. Neurología $11: 144$ 